\title{
Marital Status, Religiosity, And Experience As A Predictor Of Ethical Awareness Among Accounting Professionals
}

Javad Gorjidooz, Embry-Riddle Aeronautical University, USA

Cindy Greenman, Embry-Riddle Aeronautical University, USA

\begin{abstract}
Many corporations and their accountants have taken ethics for granted. This oversight has led to the closing of companies such as Enron and WorldCom. Accountants are placed in positions of having to render ethical decisions daily, and when they lose sight of ethical values, the dissolution of corporations can occur.

The goal in this quantitative research is to investigate the relationship between the independent variables of marital status, religiosity, and years of work experience and the dependent variable of ethical decision-making. Eighty-three members of the Michigan Association of Certified Public Accountants (MACPA) completed an internet-delivered survey on ethical dilemmas. Because they were contacted through the MACPA weekly E-newsletter, the respondents were those members who chose to accept the weekly electronic newsletter and who read it. The 83 participant responses were saved within Survey Monkey and extracted by the authors.
\end{abstract}

A nonparametric Kruskal-Wallis test examined differences in mean rank order of ethical decisionmaking scores among the marital status groupings and revealed no significant differences in mean ranks $\left(\chi^{2}(4, N=83)=3.810, p=.432\right)$ or among the years of work experience $\left(\chi^{2}(5, N=83)=\right.$ $7.768, p=.170)$. Based on results of the tests, the hypothesis that there is no relationship between ethical decision-making and marital status and between ethical decision-making and years of work experience cannot be rejected. A Spearman correlation analysis revealed no significant association ( $r h o=-0.084, p=0.226, n=83$ ) between ethical decision-making and religiosity. Based on the results of these and related tests, the hypothesis that there is no relationship between ethical decision-making and religiosity could not be rejected. The results from this study have added to the limited literature on ethical decision-making and three variables of marital status, religiosity, and years of work experience. The authors' recommendation for future research is to conduct studies within different professional organizations and with additional variables including gender, sexual orientation, age, and self-assessments. Also, given the small response size of this study, a larger, more representative sample size would give the study more credibility.

Keywords: Marital Status; Religiosity; Ethical Decision-Making; Accounting Professional; Kruskal-Wallis Test

\section{INTRODUCTION}

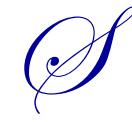

ince 2000, accounting scandals involving Enron, WorldCom, Tyco, and other companies have led to reforms in the accounting profession (Cavaliere, Mulvaney, \& Swerdlow, 2010; Mantzke, Carnes, \& Tolhurst, 2005). Some reforms have involved oversight and laws, and other reforms have involved a renewed attention to principles, morals, and ethical values. In the aftermath of such scandals, the pressure for ethical or moral transparency has increased (Stedham, Yamamaura, \& Beekun, 2007). The need to balance economic performance and social performance often leads to ethical dilemmas. Determining and maintaining the correct balance is becoming more complicated as organizations operate in an environment characterized by complexity, competition, and social obligations (Stedham, Yamamaura, \& Beekun, 2007). 
A consensus is forming on the types of responses needed when ethical dilemmas arise in organizations (Cheffers \& Pakaluk, 2005). An accountant cannot simply follow rules (Cheffers \& Pakaluk, 2005). Professional accountants must maintain the code of accounting ethics as principles, conduct themselves as professionals, and take pride in their work (Cheffers \& Pakaluk, 2005). These responses (principles, professionalism, and pride) are sometimes referred to as the "three P's" of reform (Cavaliere, Mulvaney, \& Swerdlow, 2010; Cheffers \& Pakaluk, 2005).

Since the highly publicized scandals in the business world (WorldCom, Enron, and Tyco, for example), business ethics has received considerable attention (Simmons, 2011). As these scandals point out, unethical behavior is costly to the employees, the firm, and the investors. In the Enron scandal alone, 25,000 people lost their jobs and investors lost over $\$ 1.2$ billion (Cheffers \& Pakaluk, 2005). In the midst of all the ongoing corporate corruption, there has been a great interest in discussing the morals of the business world and what factors influence a person's ethical and moral values (Keller, Smith, \& Smith, 2007; Pollara, 2008; Trevino, Weaver, \& Brown, 2008).

Ethics is an overarching human concern covering the entire area of human life (Duska \& Duska, 2007). Moral values aid individuals in making decisions about whether an act is moral or immoral. Ethics can be based on natural law, religious beliefs, parental or family influences, education, work or life experiences, or culture (Keller, Smith, \& Smith, 2007). Ethical decision-making is a process of identifying a problem, generating alternatives, and then choosing among the alternatives (Guy, 1990). The alternative that is selected should elicit the most important ethical values while also reaching the desired result (Cheffers \& Pakaluk, 2005).

Accounting, as a human pursuit, has an ethical feature. There is a good deal of research in the area of ethics and accounting (Abdolmohammadi \& Ariail, 2009; Alleyene, Devonish, Nurse, \& Cadogan-McClean, 2006; Been \& Bernardi, 2005; Bolt-Lee \& Moody, 2010; Cheffers \& Pakaluk, 2005; Duska \& Duska, 2007); however, there is little research available on the relationship of personal factors to ethical behavior in the accounting profession. Factors, such as gender, religion, and work experience, may be related to a person's ethical values (Keller et al., 2007), but, researchers have not investigated the relationship of marital status (now married, widowed, divorced, separated, never married), religiosity (dedication to one's own personal faith), and the years of work experience (number of years participating as a working professional accountant) as an accounting professional to the ethical decisions that accountants make.

\section{STATEMENT OF THE PROBLEM}

Accountants are placed in a position of having to render ethical decisions daily, and when they lose sight of ethical values, it can be very costly to their firms, their employees, and their investors. The problem being addressed is that many of the large corporations and their accountants have taken integrity for granted, leading to the annihilation of entire corporations (Bolt-Lee \& Moody, 2010; Cavaliere, Mulvaney, \& Swerdlow, 2010; Tinkler, 2005). According to Duska \& Duska (2007), it is a fact that accounting plays an indispensable role in the U.S. economy and throughout the economically developed world.

On a daily basis, the accounting profession has to make economical and ethical decisions, making it imperative to identify those factors that impact ethics in order to enhance training, hiring, and continuing education (Bolt-Lee \& Moody, 2010; Mantzke, Carnes, \& Tolhurst, 2005; Vitell, 2009). To be successful, professionals in the accounting field need to have an ethical framework in order to have the appropriate perspective for appropriate decision-making (Kranacher, Riley, \& Wells, 2011). Failure to convey appropriate ethical standards in the workplace will most assuredly hamper the profession's time-honored commitment to serve the public good (Keller et al., 2007).

Past researchers have stated that future research into the area of accounting ethics is warranted and that it should have a broad demographic profile of the samples that include working professionals rather than students (Conroy \& Emerson, 2004; Keller et al., 2007; Persons, 2009; Vasconcelos, 2009). Student samples have been used in many studies in the testing of ethical decision-making and individual integrity. This could limit the capability to generalize those results to the professional population given the limited studies involving working professionals (Albaum \& Peterson, 2006; Cavaliere, Mulvaney, \& Swerdlow, 2010; Persons, 2009). 
The purpose of this cross-sectional quantitative study is to investigate the relationship of marital status, religiosity, and years of experience as a professional accountant and their influences on ethical decision-making. This study expanded the understanding of ethics by investigating the impact of several variables on ethical decisionmaking. With a broader understanding of what impacts ethical decisions, better specialized educational and training programs for accounting professionals and trainees can be developed. This study also added to the body of knowledge concerning ethical decision-making of professional accountants in relation to the stated variables.

Participants included a subsample of the 13,157 members of the Michigan Association of Certified Public Accountants who currently receive the organizations e-newsletter. The independent variables were defined as marital status, religiosity, and years of experience as a professional accountant. The dependent variable was defined as ethical decision-making. Participants completed a survey using 25 vignettes, based on previously validated instruments (Conroy \& Emerson, 2004; Fritzsche \& Becker, 1982; Plante \& Baccaccini, 1997; Shumway \& Waldo, 2011), asking about demographic variables, religiosity, and ethical decision-making.

A power analysis was run in order to determine the required sample size for this research study using the G*Power computer software. As will be discussed in detail below, the two statistical methods used were KruskalWallis and Spearman rank correlation coefficients, two nonparametric testing methods. Two-tailed tests, an alpha level of .05 , desired power of .80 , and medium effect sizes of .30 were specified in the analyses. Using these specifications, in the $\mathrm{G}^{*}$ Power software, it was determined that a minimum required sample size to achieve adequate statistical power in this study was 82 assuming a correlation.

There is a significant amount of research on ethical decision-making; however, the amount of that research that addresses specifically what impacts the decision-making process among accounting professionals is lacking. This study, therefore, examined the ethical decision-making process by studying the impact that religiosity, years of experience as an accounting professional, and marital status have on that process. By determining the impact of these variables, it added to the body of knowledge in regard to ethical decision-making in the accounting profession and help in defining factors to assist in the education of future accountants and the continuing education of current accountants.

\section{SIGNIFICANT PRIOR RESEARCH}

\section{Religion and Ethics}

There are many studies focused on the intertwining of religious beliefs and everyday business affairs. The idea that education of future management must not limit itself simply to educate the students on how to earn a living, but to include in their education how to be socially productive, is something that has been suggested through prior research (Epstein, 2002; Lowery \& Beadles, 2009; Corner, 2009). Educators can assist in preparing students to consider the possibility that they live productive, fulfilling lives where business activities and religious commitment are not an oxymoron, but work together as parts of a meaningful life (Epstein, 2002).

Lowery's and Beadles' study focused on business professionals on the effect of religiosity on ethics. This study, assessed from a Christian perspective, concluded that religiosity was a significant predictor of moral values within the workplace (Lowery \& Beadles, 2009). The evidence from their research showed that for those individuals who showed a high strength of religiosity, there was a more demanding view of ethics and unethical behaviors in the workplace than those who did not show much strength in their faith.

Yi Hui Ho (2009), in a journal article, focused on examining the association between ethical-reasoning and religious beliefs. Ho used 449 undergraduate accounting students in Taiwan. He used an anonymous questionnaire that was strictly voluntary. Of those who responded, 273 said they did not consider themselves to be affiliated with religion in any way. Of the 154 students who said that they did consider themselves religious, $79 \%$ of them named Buddhism as their major religion.

Ho used the Defining Issues Test (DIT) developed by Rest in 1979 to measure individuals' ethical reasoning ability. This test looked at ethical-reasoning of the participants by providing hypothetical scenarios of 
different ethical dilemmas. Some critics have argued that this test is not accurate because it does not give corporate specific scenarios, but rather generalized scenarios. The critics argue that if the test is being given to accounting students, it should have accounting specific dilemmas. However, many studies have relied on the DIT to evaluate the ethical judgments of accounting students and professionals.

In his conclusion, Ho stated, "Religious beliefs are significantly correlated with accounting students' ethical-reasoning abilities. Therefore, higher education institutions may encourage or provide assistance for accounting students to discover their religious orientation and strengthen belief in their religious affiliation during their college study" (Ho, 2009, p. 675). The researcher also noted that the results should help other studies and assist in validating how religious belief systems can influence ethical reasoning and accounting integrity.

The influence of religion on ethics was researched extensively. But, “... despite extensive work in this area, there is little consensus concerning the basis or standards of 'good' or ethical behavior and the reasons behind them" (Kim et al., 2009, p. 115). Ethical standards may be assumed or religious values may be considered, but as previously stated in this literature review, there is nothing normal or nothing to be assumed when it comes to moral values and the influence religion may have on it.

\section{Marital Status and Ethics}

The idea of marital status having any kind of effect on ethical decisions has not been researched a great deal. There have been studies done on the effect of marital status and quality of life (Tang, 2007), romance in the workplace among married and unmarried co-workers (Boyd, 2010), and marital status and birth order (Rawwas \& Isakson, 2000). Pasewark and Viator (2006) studied the conflict between the home-life and work-life of accountants. Sharma (2009) found that, in general, married adults are better adjusted than unmarried adults and tend to have a higher rate of job satisfaction than their unmarried counterparts. But, when it comes to researching the affect that marital status may have on ethical decisions, there was not a generous amount of research to be found.

Serwinek (1992) studied the ethical attitudes of subjects using, age, gender, marital status, level of education, number of dependent children, the region of the country they lived in, and number of years they had been working at their current job as predictors. The researcher was looking at the ethical attitudes of workers within a small business organization and analyzing if any demographic information about those individuals could predict their ethical beliefs. Serwinek found that age was the most influential indicator, with gender also showing a strong influence. Results also showed that marital status had no influence on ethical perceptions. "A look at the regression model appended leads to the conclusion that there is no difference in ethical perceptions that can be attributable to marital status, the having of dependent children, or years on the job" (Serwinek, 1992, p. 561).

Caused by the accounting scandals of the past decade and the general public's mistrust of the U.S. business community, Stephen Baglione (2008) researched the comparison of internal morals and strong and positive values with external assessments of business partners on honesty, ethics, and customer needs. Ethics and lucrative businesses have been positively linked because it encourages and stimulates workers, while building trust that retains employees. Baglione also indicated that when people feel that they have been treated unethically, they may feel more satisfied, happier, less upset, and less guilty when they engage in unethical behavior toward their employers. A survey was developed and was given to 99 graduate students from four MBA classes. In his conclusion, Baglione found that most of the unethical situations stemmed from competitiveness in the firm since profitability, growth, and wealth goals are established upon them. With regard to marital status, Baglione found no significant differences between the attitudes of the married students and those who were not married (2008).

\section{Work Experience and Ethics}

With experience come promotion and leadership responsibilities. Ethics at the business level starts with the top of the pyramid. The Board of Directors, the Audit Committee, executives, managers, secretarial, and the factory line personnel are the living, breathing epitome of ethics within the organization (Kranacher, Riley, \& Wells, 2011). Through the passing of the Sarbanes Oxley Act of 2002, the position of CFO (Chief Financial Officer) has become one of the riskiest jobs in America (Cunningham, 2005). Along with that risk comes the responsibility of being the 
keeper of the internal controls and "corporate conscience" of the organization (p. 8). Accounting executives usually find themselves in the situation of being the culture's ethical yardstick. As a result, they have an obligation to set the right ambiance and criterion (2005).

In many corporate scandals (i.e., Enron, WorldCom, Tyco, etc.), management has claimed ignorance to the ethical troubles in their organizations. Given that senior management is an essential part to the success of an organization, they are also a part of the ethics of an organization. A study by Trevino, Weaver, and Brown (2008) investigated the idea that senior management developed a more positive perception of business ethics than the lower level employees due mainly to their management status, their responsibility to protect the firm's image, and their being out of touch with the ethical attitude in the organization. The authors proposed the idea that there is a tendency among senior managers to perceive the good when it comes to organizational ethics. When looking at senior management compared with lower-level employees, there is a great divide in the different role definitions connected to organizational tasks and social groups. There is an inherent economic conflict between the two groups. In many organizations, senior managers are far removed from low-level employees because executive level pay has grown to unprecedented levels, while the lower-level employees are barely receiving cost of living adjustments (Trevino et al., 2008). This divide between the employee groups leads to further issues. As members of different identity groups with differing roles, the lower-level employees, along with senior management, are likely to focus on different concerns and see their organization from different perspectives. In their study, Trevino et al. (2008) concluded that senior management revealed a more favorable view on the ethical attitudes in their organizations.

In a study that focused on the influence of the workplace, Taylor and Curtis (2010) explored the world of public accounting and the likelihood of whistleblowing in that arena. There have been very few studies that have contemplated whistleblowing in public accounting, although many companies have recently made confidential reporting outlets available to their employees. Their study concentrated on accounting professionals and evaluated the focus of commitment between colleagues and their firm's ethical reputation. In their conclusion, Taylor and Curtis detail how this study supported the ideas that whistleblowing intentions were greater when the participant achieved a higher level of professional identity. This was true with the higher level of responsibility and longer length of employment with the establishment.

A study by Abdolmohammadi and Ariail (2009) focused on practicing accountants in the State of Georgia. They sent questionnaires to industrial CPAs and those in private practice. The researchers distributed 582 surveys and received 314 responses. This study investigated the variables of gender, public practice compared with industrial management, political orientation, ranking in the profession, educational level, and their influence on moral reasoning. The authors used the DIT, a generic instrument used to measure moral reasoning. They used the full-test version of the DIT to collect data on the participants' moral reasoning. The sampling consisted of a fairly even amount between public practice and industry, thus giving the researchers no bias in that area. The results of this study indicated that there was no significant difference in the moral-reasoning between those of different professional ranks. The research also identified no significant difference between those in public practice relative to those who work in industry. The only significant difference shown in the research was between those CPAs with graduate degrees compared with those with only an undergraduate degree. The authors do suggest that further research should be done to investigate the moral reasoning of CPAs using different testing instruments than the one they used.

Much research has been done on the subject of ethics. Many different variables were studied trying to get a better understanding of the definition of ethics, what factors influence ethics, and what can change those factors. This study focused on the religious effects, the marital status, and the years of work experience.

\section{METHODOLOGY}

In this study, the authors utilized a cross-sectional quantitative research method with a structuredundisguised survey design. The survey that was utilized is classified as structured, with limited choices of responses and no open-ended questions. The survey method was chosen due to the quick, inexpensive, and efficient nature of accessing information about the population. Over the past 50 years, and in particular, the last two decades, research employing survey techniques has become quite scientific and accurate (Zikmund, 2003). 
The cross-sectional method was chosen for its ease of use. This approach is less expensive to conduct and takes place over a much shorter time span than other methods. The main disadvantage to this approach is the lack of comparability and reveals nothing about the continuity of development (Salkind, 2006). This method was appropriate since a relationship was assessed between variables without any experimental manipulation.

In this study, there were three independent variables which were evaluated to determine if any or all were perceived to be correlated to the dependent variable. Marital status and years of work experience were based on participants' response to demographic questions on the survey, with marital status simply asking the participant to select one of the given relationship statuses. The number of years of professional experience was based on the participants response to a range of (1) zero to five years, (2) six to 10 years, (3) 11 to 15 years, (4) 16 to 20 years, (5) 21 to 25 years or (6) more than 25 years. Religiosity was scored according to the Santa Clara Strength of Religious Faith Questionnaire (SCSRFQ; Plante \& Boccaccini, 1997). This survey instrument was used to measure the participants' strength of religious faith.

Numerical scales have numbers, rather than 'semantic space' or verbal descriptions as response options to identify categories. If the scale items have five response positions, the scale is called a 5-point numerical scale; with seven response positions, it is called a 7-point numerical scale; and so on. In practice, researchers have found that for educated populations, a scale with numerical labels for intermediate points on the scale is as effective a measure as the 'true' semantic differential. (Zikmund, 2003, p. 315)

A 25-item vignette incorporating a Likert-type scale was adopted from previously validated research done by Conroy and Emerson in 2004 (Permission granted). There are a few descriptive and demographic variables contained in the survey. These were only used to describe the participants and were not analyzed for any moderating effect. The survey was Internet-based and coordinated with the Michigan Association of Certified Public Accountants.

Data analysis for this study used the Spearman Rank Order correlation test for determining if there was a relationship between religiosity score and ethical decision-making score. Additionally, the study utilized a comparative design to examine potential influences on ethical decision-making through a Kruskal Wallis analysis of variance test. The Kruskal Wallis test was conducted to examine whether the median ethical decision-making score varied by years of experience and marital status.

For the comparative study, the ethical decision-making score was the dependent variable and the independent variables consisted of the years of experience and marital status. Each of the independent variables was independent from one another, meaning that the inclusion of one participant in a specific category did not affect the inclusion of another participant in the same or different category. However, it is likely that marital status and years of experience were not completely "independent" of one another since the more work experience, the older the individual and, hence, the more likely they are to be married.

\section{DATA}

This Internet-based survey was conducted through the Michigan Association of Certified Public Accountants (MACPA), a professional accounting organization. The CPAs and affiliated accounting professionals that make up this organization are diversified throughout the profession. The members include those in the corporate, government, academic, and private sectors of the industry. The age range of the members is from the student membership of 18 years old to retired members of the profession in their 80s (Membership Source, MACPA).

The survey link for this study was included in the weekly E-Newsletter to a computerized random selection of 3,000 members who received the weekly E-Newsletter and read it. A follow-up personal email was sent directly to the 3,000 recipient members one week after the initial E-Newsletter. This was done in order to encourage greater participation and obtain the largest response rate possible. Only 83 members responded to the email requests to participate. Responses were saved in the Survey Monkey database and extracted for analysis using SPSS Version 19 software as well as Microsoft Excel 2010. 


\section{SIGNIFICANCE OF THIS STUDY}

It is the purpose of this study to examine the relationship of marital status, religiosity, and years of experience to ethical decision-making. In recent years, the research of ethics in accounting has covered a wide array of topics (Dalton, Hill, \& Ramsay, 1997; Fasci \& Valdez, 2004; Ho, 2009; Lowe, 1987). This study focused on accountants' answers to various ethical situations in the form of 25 vignettes in order to investigate to what extent, if any, a relationship between marital status, religiosity, and level of experience and ethical decision-making exists. This investigation fills a gap in the research and adds to the body of knowledge concerning ethical decision-making of professional accountants in relation to the stated variables. The corporations of today have acknowledged the significance of hiring workers, managers, and leaders who are morally mature and who are able to make ethical decisions and resolve moral dilemmas (De George, 1999). With that information, better educational classes, sensitivity training programs, and understanding of the influences of ethical decision-making among the accounting profession could be developed.

The review of literature encourages the need to investigate ethics and the variables that influence an individual's ethical decisions (Fraedrich, 1993; Joseph, Berry, \& Deshpande, 2010; Lopez, Rechner, \& OlsonBuchanan, 2005). An issue with the review of literature was that the findings were not consistent enough to warrant the advancement of definitive conclusions (Macve, 2010; McManus, 2009). Another challenge was the fact that some previous work utilized student samples to research ethical decision-making and individual principles, which could limit the capability to generalize those results to the professional population (Albaum \& Peterson, 2006; Cavaliere, Mulvaney, \& Swerdlow, 2010; Persons, 2009).

This quantitative research focused on the ethical decision-making of working professional accountants in regard to the relationships among the stated variables. The body of research supported the need for a study that focused on gaining an understanding about the variables and accountants' ethical decision-making given the stated variables and their relationship (Vittell, 2009; Wilson, 2008). Understanding the elements of ethical decisionmaking is vital in the education of future accountants and the continuing education of current professionals (Trevino, 1999).

\section{EMPIRICAL RESULTS}

The purpose of this cross-sectional quantitative study was to investigate the relationship of marital status, religiosity, and years of experience as a professional accountant and their influences on ethical decision-making. The sample consisted of working accounting professional members of the MACPA who are receiving the electronic newsletter from the organization.

The first research question was: To what extent, if any, is there a relationship between marital status and ethical decision-making among a randomly selected sub-sample of MACPA members who receive and read the MACPA E-newsletter based upon answers to 25 vignettes of ethical dilemmas? The null hypothesis associated with this question was not rejected and it was concluded there was no statistically significant relationship between marital status and ethical decision-making.

A Kruskal-Wallis test was conducted to determine if there was a difference in ethical decision-making scores based on marital status. Kruskal-Wallis test was utilized because the main independent variable - marital status - included ranked scores and the distributions for the test variable could not be assumed as normally distributed. Table 1 shows the mean of the totaled ethical decision-making score for each of the marital status categories. The Kruskal-Wallis examined differences in mean rank order of ethical decision-making scores among the marital status groupings, with no significant differences in the mean ranks with $\chi^{2}(4, \mathrm{~N}=83)=3.810$ and $p=$ .432. Based on results of the tests, the hypothesis that there is no relationship between ethical decision-making and marital status cannot be rejected. Therefore, it was concluded that there was no statistically significant relationship between marital status and ethical decision-making. 
Table 1: Ethical Score for Each Marital Status

\begin{tabular}{|l|c|c|c|}
\hline \multicolumn{1}{|c|}{ Marital Status } & Mean Score & N & Standard Deviation \\
\hline Skipped Question & 43.0000 & 1 & 10.54038 \\
\hline Currently Married & 49.9804 & 51 & 17.51571 \\
\hline Divorced & 54.4000 & 5 & 31.11270 \\
\hline Widowed & 61.0000 & 2 & 12.40960 \\
\hline Never Married & 56.2083 & 24 & 12.19389 \\
\hline Total & 52.2289 & 83 & \\
\hline
\end{tabular}

The second research question was: To what extent, if any, is there a relationship between religiosity and ethical decision-making among a randomly selected sub-sample of MACPA members who receive and read the MACPA E-newsletter based upon answers to 25 vignettes of ethical dilemmas and spirituality questions?

Table 2 breaks down the religiosity questions individually, displaying a brief description of each individual question from the Santa Clara Strength of Religious Faith Questionnaire (SCSRFQ), the mean response, standard deviation, and the response count to the individual questions. Respondents were asked to rank the degree to which they agreed with the statement using a five-point Likert scale (ranging from strongly disagree, "1," to strongly agree, "4"). Therefore, higher average overall scores suggest a higher degree of religiosity or strength of religious conviction. Table 3 shows the breakdown of the statistics for the Spearman rank correlation between the ethical decision-making score and religiosity. The Spearman correlation analysis revealed no significant association $($ rho $=$ $0.084, \mathrm{p}=0.226, \mathrm{n}=83$ ) between ethical decision-making and religiosity. The null hypothesis associated with this question was not rejected and it was concluded that there was no statistically significant relationship between religiosity and ethical decision-making.

Table 2: Summary Statistics of Responses to Religiosity

\begin{tabular}{|l|l|c|c|c|}
\hline \multicolumn{1}{|c|}{ Question } & \multicolumn{1}{|c|}{ Brief Description } & Mean Response & Standard Deviation & N \\
\hline 1 & My faith is extremely important to me & 3.01 & 1.059 & 82 \\
\hline 2 & One Pray Daily & 2.59 & 1.122 & 82 \\
\hline 3 & Faith is inspirational & 2.89 & 1.006 & 82 \\
\hline 4 & Faith provides purpose & 2.85 & 1.075 & 79 \\
\hline 5 & Active in faith and church & 2.49 & 1.097 & 81 \\
\hline 6 & Faith is part of me & 2.96 & 1.054 & 81 \\
\hline 7 & Relationship with God is imp. to me & 3.01 & 1.135 & 81 \\
\hline 8 & Enjoy others who share faith & 2.86 & 0.9321 & 81 \\
\hline 9 & Faith is a comfort to me & 2.84 & 1.054 & 81 \\
\hline 10 & Faith impacts decisions & 2.80 & 1.042 & 81 \\
\hline
\end{tabular}

Table 3: Spearman Rank Correlation Results between Ethical Score and Religiosity

\begin{tabular}{|l|l|c|c|}
\hline \multicolumn{2}{|c|}{ Spearman Rank Correlation } & Ethical Decision-Making Score & Religiosity Score \\
\hline \multirow{3}{*}{ Spearman's rho Ethical Score } & Correlation Coefficient & 1.000 & -0.084 \\
\cline { 2 - 4 } & Sig.(1-tailed) & & 0.226 \\
\cline { 2 - 4 } & $\mathrm{N}$ & 83 & 83 \\
\hline \multirow{3}{*}{ Religiosity Score } & Correlation Coefficient & -0.084 & 1.000 \\
\cline { 2 - 4 } & Sig.(1-tailed) & 0.226 & 83 \\
\cline { 2 - 4 } & $\mathrm{N}$ & 83 & \\
\hline
\end{tabular}

The third research question was: To what extent, if any, is there a relationship between years of work experience and ethical decision-making among a randomly selected sub-sample of MACPA members who receive and read the MACPA E-newsletter based upon answers to 25 vignettes of ethical dilemmas?

Table 4 compares the totaled ethical decision-making score with each of the years-of-experience categories. The Kruskal-Wallis examined differences in mean rank order of ethical decision-making scores among the years of work experience groupings with $\chi^{2}(5, \mathrm{~N}=83)=7.768$ and $p=.170$. Based on results of the tests, the hypothesis that there is no relationship between ethical decision-making and years of work experience cannot be rejected. Therefore, it was concluded that there was no statistically significant relationship between the years of work experience and ethical decision-making. 
Table 4: Comparing Ethical Scores and Years of Work Experience

\begin{tabular}{|l|c|c|c|}
\hline Years of Work Experience & Mean Score & N & Standard Deviation \\
\hline 0-5 years & 58.1364 & 22 & 13.81268 \\
\hline 6-10 years & 49.1667 & 6 & 16.09244 \\
\hline 11-15 years & 48.6364 & 11 & 8.11508 \\
\hline 16-20 years & 56.2857 & 7 & 15.57470 \\
\hline 21-25 years & 53.6000 & 10 & 10.92601 \\
\hline 26+ years & 48.0000 & 27 & 9.02986 \\
\hline Total & 52.2289 & 83 & 12.19389 \\
\hline
\end{tabular}

\section{CONCLUSION}

This cross-sectional quantitative study investigated the relationship of marital status, religiosity, and years of experience and their influences on ethical decision-making. The survey consisted of 25 ethical situation vignettes, the Santa Clara Strength of Religious Faith Questionnaire (SCSRFQ), and demographic questions. The sample population (3,000 members) was randomly chosen from those members of the Michigan Association of Certified Public Accountants (MACPA) who signed-up to receive the weekly electronic newsletter $(13,157$ members). Participants completed an online survey and returned 83 responses.

The finding of no statistically significant relationship was consistent with the literature on marital status influencing ethical decision-making (Lloyd et al., 2008; Serwinek, 1992; Zaid, 1997).

The finding of no statistically significant results in religiosity and ethical decision-making was inconsistent with the literature (Keller et al., 2007; Vitell, 2009).

The results indicating no statistically significance in the relationship between years of work experience and ethical decision-making were inconsistent with the findings of Rosenzweig and Fischer (1994) but consistent with the findings of Janosik (2007).

The results from this research added to the limited literature on accounting ethics and ethical decisionmaking among working professionals. More studies are recommended to assess the influences of ethics and ethical decision-making. Recommendations for future research include conducting the study within different professional accounting organizations and at other influential factors.

\section{AUTHOR INFORMATION}

Dr. Javad Gorjidooz is a professor of finance at Embry-Riddle Aeronautical University (ERAU). He has a MBA, $\mathrm{MA}$, and Ph.D. from Indiana University at Bloomington, Indiana, with majors in accounting, economics and finance. He has 25 years of experience in teaching a variety of courses in finance and economics and has written and published many articles concerning the aviation industry, including Aircraft Valuation in Dynamic Air Transport Industry and Productivity Analysis of Public and Private Airports: A Causal Investigation. His articles have been published in numerous peer-reviewed academic journals such as the Journal of Air Transportation and International Business and Economics Research Journal. Dr. Gorjidooz s paper entitled "“Fortress America” As Created by NAFTA and Its Impact on Foreign Direct Investments" was awarded the best paper presented at the Annual Meeting of the International Applied Business Research Conference in Puerto Vallarta, Mexico. E-mail: gorji0cf@erau.edu (Corresponding author)

Dr. Cindy Greenman is an assistant professor at Embry Riddle Aeronautical University in Prescott, Arizona. Dr. Greenman graduated from Central Michigan University in Mt. Pleasant, Michigan, with both a Bachelor Degree and Masters Degree. She did her doctoral work through Northcentral University in Arizona. Her dissertation was awarded the KPMG Dissertation of the year for 2012. She is a Certified Fraud Examiner and registered with the Association of Certified Fraud Examiners. E-mail: Cindy.Greenman@erau.edu 


\section{REFERENCES}

1. Abdolmohammadi, M., \& Ariail, D. (2009). A test of the selection-socialization theory in moral reasoning of CPAs in industry and practice. Behavioral Research in Accounting, 21(2), 1-12.

2. Albaum, G., \& Peterson, R. (2006). Ethical attitudes of future business leaders: Do they vary by gender and religiosity? Business and Society, 45(3), 300-321.

3. Baglione, S. (2008). The influence of internal ethics and values and external perceptions of values and needs on profitability: An empirical study of U.S. executives. Review of Business Research, 8(5), 89-95.

4. Bean, D., \& Bernardi, R. (Dec. 2005). Accounting ethics courses: A professional necessity. The CPA Journal, 30(12), 64-65.

5. Bolt-Lee, C., \& Moody, J. (October, 2010). Highlights of finance and accounting ethics research. Journal of Accountancy, 210(4), 38-41.

6. Boyd, C. (2010). The debate over the prohibition of romance in the workplace. Journal of Business Ethics, 97(2), 325-338.

7. Cavaliere, F., Mulvaney, T., \& Swerdlow, M. (2010). Teaching business ethics after the financial meltdown: Is it time for ethics with a sermon? Education, 131(1), 3-8.

8. Cheffers, M., \& Pakaluk, M. (2005). Understanding Accounting Ethics. Manchaug, MA: Allen David Press.

9. Conroy, S., \& Emerson, T. (2004). Business ethics and religion: Religiosity as a predictor of ethical awareness among students. Journal of Business Ethics, 50(4), 383-396.

10. Cunningham, C. (2005). The value of values. Financial Executive, 20(1), 8.

11. Dalton, D., Hill, J., \& Ramsay, R. (1997). Women as managers and partners: Context specific predictors of turnover in international public accounting firms. Auditing, 16(1), 29-50.

12. De George, R. T. (1999). Business ethics (5th ed.). Englewood Cliffs, NJ: Prentice Hall.

13. Duska, R., \& Duska, B. (2007). Accounting ethics. Malden, MA: Blackwell Publishing.

14. Epstein, E. (2002). Religion and business - the critical role of religious traditions in management education. Journal of Business Ethics, 38(2), 91-96.

15. Fasci, M., \& Valdez, J. (2004). A comparative profile of male and female owned small accounting practices. Journal of Small Business Strategy, 15(1), 17-31.

16. Fraedrich, J. (1993). The ethical behavior of retail managers. Journal of Business Ethics, 12(3), 207-218.

17. Fritzsche, D., \& Becker, H. (1982). Business ethics of future marketing managers. Journal of Marketing Education, Fall, 2-7.

18. Guy, M. (1990) Ethical decision-making in everyday work situations. Westport, CT: Greenwood Press.

19. Ho, Y. (June, 2009). Associations between the religious beliefs and ethical-reasoning abilities of future accounting professionals. Social Behavior and Personality, 37(5), 673-678.

20. Janosik, S. (2007). Common issues in professional behavior. National Association of Student Personnel Administrators (NASPA) Journal, 44(2), 285-306.

21. Joseph, J., Berry, K., \& Deshpande, S. (May, 2010). Factors that impact the ethical behavior of college students. Contemporary Issues in Education Research, 3(5), 27-34.

22. Keller, A., Smith, K., \& Smith, L. (2007). Do gender, educational level, religiosity, and work experience affect the ethical decision-making of U.S. Accountants? Critical Perspectives in Accounting, 18, 299-314. Retrieved from Business Elite Datasource.

23. Kim, D., Fisher, D., \& McCalman, D. (2009). Modernism, Christianity, and business ethics: A worldview perspective. Journal of Business Ethics, 90(10), 115-121.

24. Lloyd, T., Heinfeldt, J., \& Wolf, F. (2008). Corporate social responsibility from the employees' perspective: An empirical organizational analysis. Review of Business Research, 8(3), 17-24.

25. Lopez, Y., Rechner, P., \& Olson-Buchanan, J. (2005). Shaping ethical perceptions: An empirical assessment of the influence of business education, culture, and demographic factors. Journal of Business Ethics, 60(4), 341-358.

26. Lowe, H. (1987). Ethics in our 100-year history. Journal of Accountancy, 163(5), 78-87.

27. Lowery, C., \& Beadles, N. (2009). Differences between work-related ethics and non-work ethics, and the effects of religiosity. Journal of Managerial Issues, 21(3), 421-435.

28. Macve, R. (2010). Conceptual frameworks of accounting: some brief reflections on theory and practice. Accounting and Business Research, 40(3), 303-308. 
29. Mantzke, K., Carnes, G., \& Tolhurst, W. (Sept. 2005). Incorporating professional ethics throughout an accounting curriculum. The CPA Journal, 28(9), 66-67.

30. McManus, K. (2009). The relationship between ethical leadership, attachment orientation and gender in organizations. (Unpublished doctoral thesis). Walden University.

31. Michigan Association of Certified Public Accountants. (2010). Membership Details.

32. Pasewark, W., \& Viator, R. Sources of work-family conflict in the accounting profession. Behavioral Research in Accounting, 18(1), 147-165.

33. Persons, O. (2009). Using a corporate code of ethics to assess students' ethicality: Implications for business education. Journal of Education for Business, 357-366.

34. Rosenzweig, K., \& Fischer, M. (1994). Managing earnings. Management Accounting, 22 (4), $62-67$.

35. Salkind, N. (2006). Exploring Research (6 ${ }^{\text {th }}$ ed.). Upper Saddle River, NJ: Pearson-Prentice Hall.

36. Serwinek, P. (1992). Demographic \& related differences in ethical views among small businesses. Journal of Business Ethics, 11(7), 555-567.

37. Sharma, J. (2009). Job satisfaction of university teachers: an empirical study. Journal of Services Research, $9(2), 51-80$.

38. Shumway, B., \& Waldo, M. (October, 2011). Client's religiosity and expected working alliance with theistic psychotherapists. Psychology of Religion and Spirituality, doi: 10.1037/a0025675

39. Simmons, L. (January, 2011). The aftermath of public attention on accounting improprieties: Effects on securities class action settlements. Journal of Accounting and Public Policy, 30(1), 22-49.

40. State of Michigan, Department of Labor. (2009). Labor and Statistics Report.

41. Stedham, Y., Yamamaura, J., \& Beekun, R. (April, 2007). Gender differences in business ethics: Justice and relativist perspectives. Business Ethics, 16(2), 163-174.

42. Tang, T. (2007). Income and quality of life: does the love of money make a difference. Journal of Business Ethics, 72(4), 375-393.

43. Taylor, E., \& Curtis, M. (2010). An examination of the layers of workplace influences in ethical judgments: Whistleblowing likelihood and perseverance in public accounting. Journal of Business Ethics, 93(1), 21-37.

44. Trevino, L., Weaver, G., \& Brown, M. (2008). It's lovely at the top: hierarchical levels, identities, and perceptions of organizational ethics. Business Ethics Quarterly, 18(2), 233-252.

45. Vasconcelos, A. (2009). Spiritual development in organizations: a religious based approach. Journal of Business Ethics, 93(10), 607-622.

46. Vitell, S. (2009). The role of religiosity in business and consumer ethics: a review of the literature. Journal of Business Ethics, 90(10), 155-167.

47. Wilson, B. (2008). Predicting intended unethical behavior of business students. Journal of Business Ethics, 84(2), 187-195.

48. Zikmund, W. (2003). Business Research Methods ( $7^{\text {th }}$ ed.). Mason, OH: South-Western Cengage Learning. 
NOTES 